\title{
The social impacts of bedbug infestation as an emerging public health issue: a case report
}

Ismaeil Alizadeh ${ }^{1}$, Mohammad Amin Gorouhi ${ }^{2}$, Abbas Aghaei Afshar ${ }^{3}$, Abedin Iranpour $^{4}$

${ }^{1}$ M.Sc. in Medical Entomology and Vector Control, Department of Vector Biology and Control, School of Health, Kerman University of Medical Science, Kerman, Iran

${ }^{2} \mathrm{Ph} . \mathrm{D}$. in Medical Entomology and Vector Control, Assistant Professor, Department of Vector Biology and Control, School of Health, Kerman University of Medical Science, Kerman, Iran

${ }^{3}$ Ph.D. in Medical Entomology and Vector Control, Associate Professor, Leishmaniasis Research Center, Kerman University of Medical Sciences, Kerman, Iran

${ }^{4} \mathrm{Ph} . \mathrm{D}$. in Health Education and Promotion, Assistant Professor, HIV/STI Surveillance Research Center, and WHO Collaborating Center for HIV Surveillance, Institute for Futures Studies in Health, Kerman University of Medical Sciences, Kerman, Iran

Type of article: Case report

\begin{abstract}
Introduction: Bedbugs (Cimex spp.) are a public health problem and an urban pest that require blood meal from humans, other mammals or birds to survive. Bedbugs constitute an emerging public health problem and infestations have been reported globally. This paper reports three cases of social health problems caused by bedbugs in three residential buildings in Kish Island, Dezful, and Ahvaz in southern Iran.

Case presentation: Case 1; A 42-year-old male living in Dezful city had a bedbug infestation in his house (September 2018). He developed a phobia (entomophobia) about bedbugs. Case 2; A 36-year-old man and 33year-old woman living in Ahvaz city had a bedbug infestation in their house (August 2017). The woman was very concerned about the bedbug infestation in the house and she had entomophobia, stress, anxiety, insomnia and paranoia; this issue caused resentment and hence conflict between the couple. Case 3: A 25-year-old woman and a 28-year-old man living in Kish Island rented a house from a 45-year-old man. The landlord was very concerned about the bedbug infestation in the house (July 2017), and claimed that the tenants were responsible for bedbugs' presence. This issue caused hostility and conflict between them. Generally, all cases had bedbug infestations in their houses and this issue caused some social health problems such as entomophobia, concern, fear, stress, anxiety, insomnia, paranoia, resentment and conflict.

Take-away lesson: Bedbugs are not vectors for infectious disease. But, with regard to our observations in the present study, bedbug infestations can produce some social health problems such as entomophobia, concern, fear, stress, anxiety, insomnia and paranoia, as well as resentment, hostility and conflict between residents in infested houses.

Keywords: Bedbug; Cimex spp.; Pest; Human; Case reports
\end{abstract}

\author{
Abbreviations / Acronyms: \\ PTSD: Post-traumatic Stress Disorder
}

\section{Introduction}

Bedbugs (Cimex spp.) are a public health problem and an urban pest. They are nocturnal hematophagous ectoparasitic insects, cryptic, wingless and reddish brown in color and approximately $5-7 \mathrm{~mm}$ in length with an ovalshaped body $(1,2)$, which require blood meal from humans, other mammals or birds to survive. Bedbugs are considered as an urban pest with public health importance in human environments. There are two species; the

\section{Corresponding author:}

Associate Professor Dr. Abbas Aghaei Afshar, Leishmaniasis Research Center, Kerman University of Medical Sciences, Kerman, Iran. Tel: +98.9130498400, E-mail: afshara2@yahoo.com

Received: May 08, 2019, Accepted: September 02, 2019, Published: December 2019

iThenticate screening: September 17, 2019, English editing: September 18, 2019, Quality control: September 21, 2019 (C) 2019 The Authors. This is an open access article under the terms of the Creative Commons Attribution-NonCommercialNoDerivs License, which permits use and distribution in any medium, provided the original work is properly cited, the use is non-commercial and no modifications or adaptations are made. 
Common bedbug, Cimex lectularius and the Tropical bedbug, Cimex hemipterus (3, 4). Bedbugs are a severe public health issue with costly, laborious, time consuming, repetitive, and embarrassing treatments. They are ordinarily nocturnal and hide in protected places (5) such as floor areas under beds, couches, mattresses, desks, walls, chairs, sofas, wooden wardrobes and wooden furniture, thus difficult to find and control the infestation (6).

Bedbug infestation can produce psychological distress including nightmares, insomnia, stress, anxiety, avoidance behaviors, anemia, paranoia and personal dysfunction (7). Furthermore, physical and mental health consequences can be common among individuals living with bedbug infestation (8). Bedbug bites are painless and cause itchy skin, but can vary between individuals. Bedbug bites are more commonly on the arms, forearms, legs, torso, neck and face (8). The pattern of bedbug biting distribution is in a linear sequence, with 3-4 bites in a line or curve; sometimes referred to as the "breakfast, lunch, and dinner" pattern (7). Bedbugs are suspected of transmitting infectious agents, but no report has yet demonstrated that they are infectious disease vectors (9). Bedbugs have been resurgent as an important public health concern in the past decade (10). This insect affects individuals across all societies and infests everywhere. Bedbugs constitute an emerging public health problem throughout the world and its prevalence is elevating worldwide as reports of bedbug infestations across diverse settings including homes, apartments, healthcare facilities, and hotels have increased (8). Indeed, bedbug infestation has been reported in different countries throughout the world; from the United States, Europe, Scandinavia, Brazil, Nigeria, Iran, Singapore, Malaysia, Korea, Thailand and Kuwait (11-20)

Factors underlying its re-emergence remain unclear, although high levels of resistance to domestic insecticides, increased human travel (international travel and migration), decreased public awareness about the bedbug biology, poor or non-existent pest management practices and global warming have contributed (11-20). Little research has been conducted regarding the prevalence of bedbug infestation in Iran (7). While the prevalence of this urban pest in other Iranian cities such as Tehran, Tabriz, Kerman, Bushehr, Mashhad, Qom, Kish Island, Bandar Abbas and Ilam is reported, the information has not been published (21). Based on its importance in public sanitation, this paper aims to report the occurrences of social health problems caused by bedbug infestation in residential houses in three areas of Iran.

\section{Case presentation}

In this study, we report some social health problems among individuals exposed to bedbug infestation in three areas: Kish Island, Dezful city and Ahvaz city in southern Iran (Figure 1).

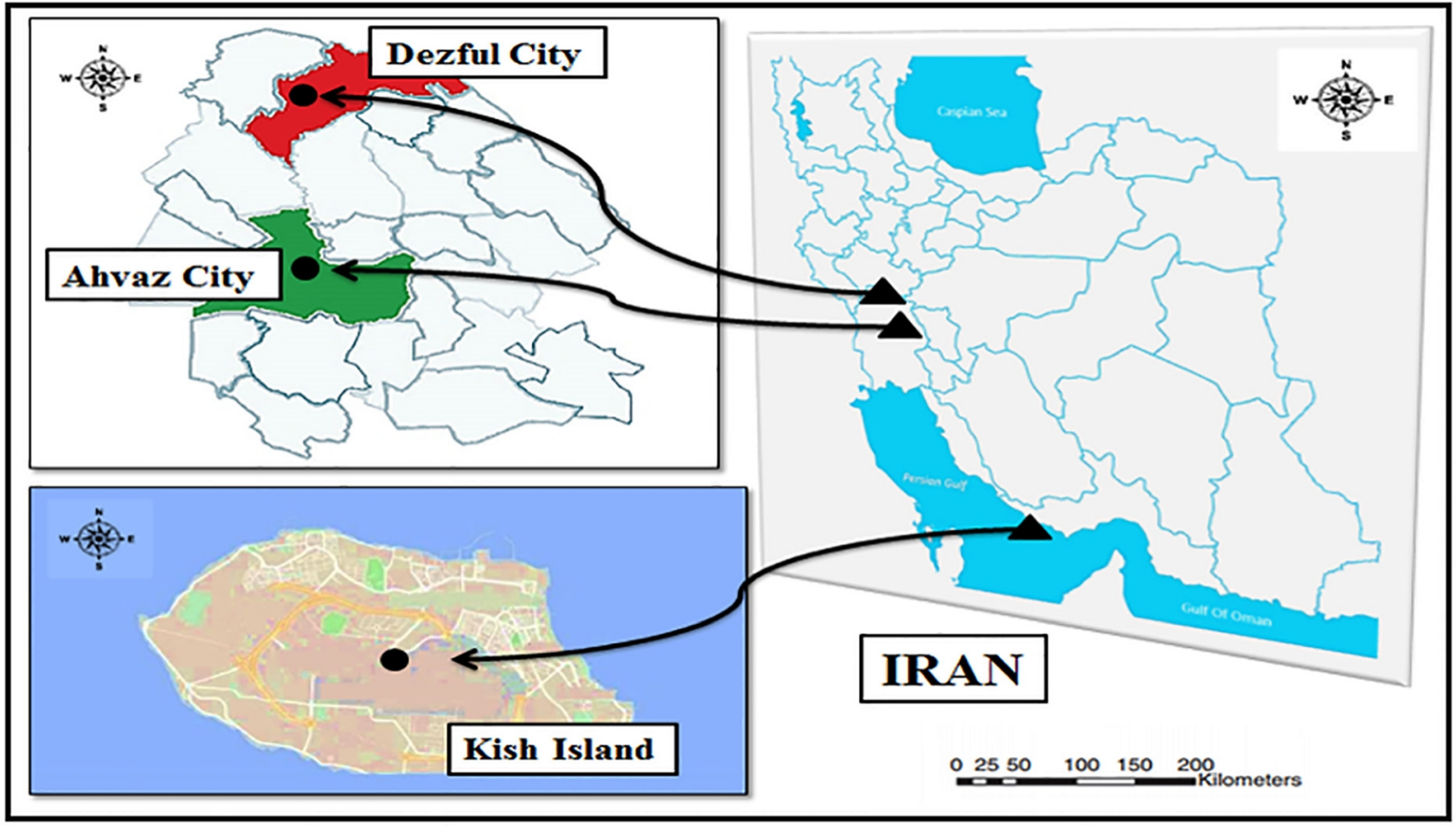

Figure 1. Location Map of the three case reports, of southern Iran 


\subsection{Case 1: Entomophobia}

A 42-year-old male who resided in Dezful city had a bedbug infestation in his house and had bedbug bite signs such as cutaneous allergic reactions and bullous reactions on parts of his body (Figure 2). He had become so concerned about the bedbug infestation that he referred to a pest control company to exterminate the pests. The bedbug infestation was eliminated from his house after a while, but he felt elimination was not completely done and his concerns and phobia about the infestation continued. He referred to the pest control company a second time. Our team (Medical Entomology experts) visited and inspected his house for the second time in September 2018 and did not find any bedbug infestation in any part of the house. It seems he had a phobia (Entomophobia in this case) of bedbug infestation. Our team assured him that his house was free of bedbugs and we recommend him a consultation with a mental health professional for his phobia.



Figure 2. Erythematous papules, some with the peculiar "breakfast, lunch and dinner" pattern. Photo by Ismaeil Alizadeh.

\subsection{Case 2: Conflict between husband and wife}

A 36-year-old man and 33-year-old woman resided in Ahvaz city and had a bedbug infestation in their house (August 2017). A bedbug infestation had already been eliminated by a pest control company in the previous year. After several months, their house was re-infested by bedbugs (Figure 3). The woman was very concerned about the bedbug infestation in the house and suffered from entomophobia, stress, anxiety, insomnia and paranoia; this issue caused hostility and hence a conflict between them.

\subsection{Case 3: Conflict between landlord and tenant}

A 25-year-old woman and a 28-year-old man living in Kish Island rented a house from a 45-year-old man. Several months after the tenants had settled in, the landlord brought a second-hand wooden wardrobe to their house. When the rental period was over, the landlord found that the house was infested by bugs. The landlord was very concerned about the bedbug infestation in the house, and claimed that the tenants were responsible for bedbugs' presence, whereas the tenants claimed that the bedbug infestation was due to the wooden locker brought in by the landlord. This issue led to hostility and conflict between them. Finally, after a medical entomologist expert's inspection of the house in July 2017, it was found that the bedbug infestation was brought to the house by the landlord (Figure 4). 


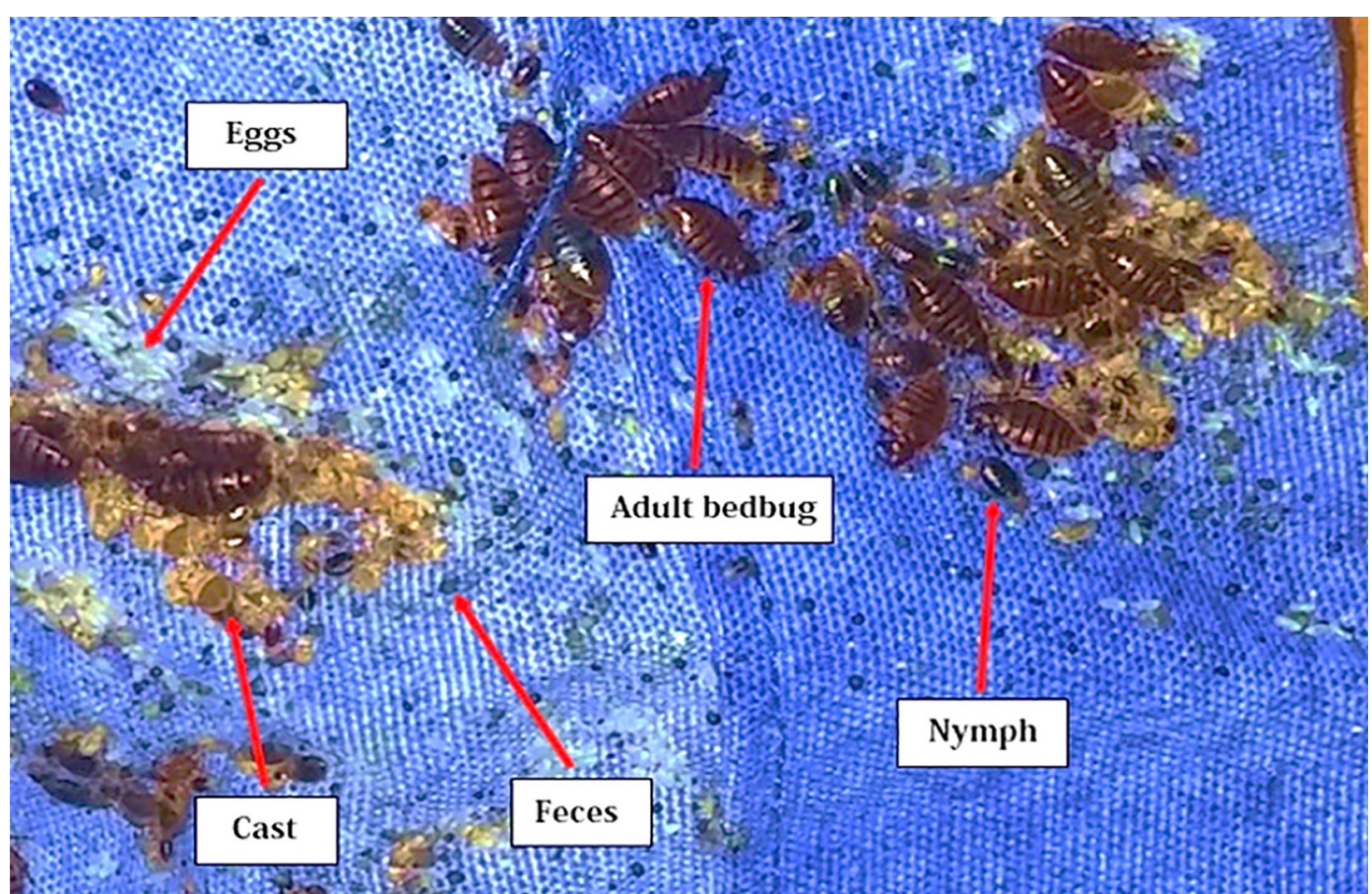

Figure 3. Presence of bedbug eggs, nymphs, adults and feces over the bed. Photo by Ismaeil Alizadeh.



Figure 4. The collected bedbug specimen (Magnification $\times 40$ ). Photo by Ismaeil Alizadeh.

\section{Discussion}

Recently, bedbug infestation has been on the increase worldwide (21). There is scant study reporting of bedbug social health problems among residents around the world and especially in Iran. This case report study found that all cases had problems due to bedbug infestation in their houses. Present studies reveal that bedbug infestation may cause social health problems such as entomophobia, concern, fear, stress, anxiety, insomnia, paranoia, hostility and conflict. Therefore, we have reported on these cases due to the lack of information about the social health problems of bed bugs. In our first case (case 1), the woman had entomophobia about bedbugs and was finally treated following recommendations from our team, in case 2; the woman had fear, entomophobia, stress, anxiety, insomnia and paranoia due to bedbug infestation and was finally treated after intervention by a pest control company and in case 3; the problem between the landlord and his tenants was resolved after a medical entomologist expert's inspection. 
Additionally, our study showed cutaneous allergic reactions and bullous reactions to bedbug bites among individuals in all cases. In general, several studies have reported hypersensitivity, cutaneous allergic reactions and bullous reactions to bedbug bites throughout the world (22). Moreover, Alizadeh et al. (2017) reported allergic reactions and dermatitis to common bedbug bites from Ahvaz, Southwest Iran (22).

The results of our study showed that fear, entomophobia, stress and paranoia was the cause among individuals who were exposed to bedbug infestation. Bedbugs are considered as a public health nuisance, which feed on humans and cause psychological distress, insomnia, anxiety, anemia, irritation and skin itching in individuals (7). Based upon the survey of Ashcroft et al., individuals residing in environments infested with bedbugs are at risk of suffering from a broad range of mental health effects, including emotional distress, discomfort, fear, flashbacks, hyper vigilance, panic, avoidance behaviors, post-traumatic stress disorder (PTSD), paranoia, and depression.

The results in this case report study showed that there is concern among residents exposed to bedbug infestation; their concern was of high level. Potter et al. (2010) reported psychological distress among people's living with bedbugs infestation (23). Based upon evidence, it suggests that infestation by the common bedbug (Cimex lectularius L.) may be a stressor that has an emotional and psychological effect (24).

Based on evidence in our study, the second-hand wooden desk introduced the bedbug infestation into the house (case 3). Presence of cockroaches and rodent infestations in housing can be associated with poor health outcomes (25), but in general, concerning bedbugs, the transfer of second-hand furniture and travelling to infected places were the most common ways to bedbug infestation (26). The findings of Wang et al. (2016) demonstrated the possible routes that bedbug infestation can be introduced including: second-hand items such as used furniture, visitors to households and neighboring households, from public places and bed wetting (27). Because of frequent tenant turnover, public housing is more at risk than other environments for bedbug epidemics (26). Similar results showed in this study (case 2) that individuals living in public housing were exposed to bedbug infestation. Elizabeth Comack and James Lyons (2011) reported landlord and tenant conflicts in Winnipeg inner-city residents. This report was similar with our result (case 3) (28). Moreover, James Lyons (2010) constantly reported conflict between family members $(28,29)$, as similar to our study (case 2$)$.

\section{Conclusions}

In summary, there is little information about social health problems caused by bedbug infestation. Therefore, our study has added further information and evidence regarding bedbug infestation problems such as entomophobia, conflict between husband and wife and conflict between tenant and landlord. In conclusion, the problems in all case reports were resolved following recommendations by experts. Finally, our study found a strong association between bedbug infestation and social health problems among residents. It is recommended to increase residents' awareness and knowledge about bedbug infestation through implementing educational programs.

\section{Acknowledgments:}

The authors are grateful to Dr. Somayeh Bahrami from Shahid Chamran University of Ahvaz, for his helpful comments on an earlier draft and reviewing the manuscript. Also, the authors wish to thank the residents of Kish Island, Dezful, and Ahvaz for their cooperation with the study.

\section{Conflict of Interest:}

There is no conflict of interest to be declared.

Authors' contributions:

All authors contributed to this project and article equally. All authors read and approved the final manuscript.

\section{References:}

1) Tawatsin A, Thavara U, Chompoosri J, Phusup Y, Jonjang N, Khumsawads C, et al. Insecticide resistance in bedbugs in Thailand and laboratory evaluation of insecticides for the control of Cimex hemipterus and Cimex lectularius (Hemiptera: Cimicidae). J Med Entomol. 2011;48(5), 1023-1030. doi: 10.1603/ME11003. [PMID: 21936321].

2) Koganemaru R, Miller DMJPB, Physiology. The bedbug problem: past, present, and future control methods. Pestic Biochem Phys. 2013;106(3):177-89. doi: 10.1016/j.pestbp.2013.05.005. 
3) Sharififard M, Alizadeh I, Jahanifard E, Wang C, Azemi ME. Chemical Composition and Repellency of Origanum vulgare Essential Oil against Cimex lectularius under Laboratory Conditions. J Arthropod Borne Dis. 2018;12(4):387-397. [PMID: 30918908]. [PMCID: PMC6423461].

4) Dang K, Doggett SL, Singham GV, Lee CY. Insecticide resistance and resistance mechanisms in bedbugs, Cimex spp.(Hemiptera: Cimicidae). Parasit Vectors. 2017;10(1):318. doi: 10.1186/s13071-017-2232-3. [PMID: 28662724]. [PMCID: PMC5492349].

5) Zhu F, Sams S, Moural T, Haynes KF, Potter MF, Palli SR. RNA interference of NADPH-cytochrome P450 reductase results in reduced insecticide resistance in the bedbug, Cimex lectularius. PloS one. 2012;7(2):e31037. doi: 10.1371/journal.pone.0031037. [PMID: 22347424].

6) Hottel BA, Pereira RM, Koehler PG. The influence of roughness and pyrethroid formulations on bedbug (Cimex lectularius L.) resting preferences. Insects. 2015;6(2):455-63. doi: 10.3390/insects6020455. [PMID: 26463196]. [PMCID: PMC4553491].

7) Alizadeh I, Sharififard M, Jahanifard E, Rajaei F, Mousavian G, Mehraghaei M. Identification, Knowledge, and Awareness of People Regarding Public Health Nuisance Insect (Cimex lectularius) in Southwest of Iran. Jundishapur J Health Sci. 2018;10(3). doi: 10.5812/jjhs.81133.

8) Ashcroft R, Seko Y, Chan LF, Dere J, Kim J, McKenzie K. The mental health impact of bedbug infestations: a scoping review. Int J Public Health. 2015;60(7):827-37. doi:10.1007/s00038-015-0713-8. [PMID: 26463196].

9) Lai O, Ho D, Glick S, Jagdeo J. Bedbugs and possible transmission of human pathogens: a systematic review. Arch Dermatol Res. 2016;308(8):531-8. doi: 10.1007/s00403-016-1661-8. [PMID: 27295087]. [PMCID: PMC5007277].

10) Goddard J, de Shazo R. Psychological effects of bedbug attacks (Cimex lectularius L.). Am J Med. 2012;125(1):101-3. doi: 10.1016/j.amjmed.2011.08.010. [PMID: 22195533].

11) 11.Lee IY, Ree HI, An SJ, Linton JA, Yong TS. Reemergence of the bedbug Cimex lectularius in Seoul, Korea. Korean J Parasitol. 2008;46(4):269. doi: 10.3347/kjp.2008.46.4.269. [PMID: 19127335]. [PMCID: PMC2612614].

12) Politi FAS, Nascimento JD, da Silva AA, Moro IJ, Garcia ML, Guido RV, et al. Insecticidal activity of an essential oil of Tagetes patula L.(Asteraceae) on common bedbug Cimex lectularius L. and molecular docking of major compounds at the catalytic site of ClAChE1. Parasitol Res. 2017; 116(1):415-424. doi: 10.1007/s00436-016-5305-x. [PMID: 27838836].

13) Haghi SFM, Behbodi M, Hajati H, Shafaroudi M. Prevalence of bedbug (Cimex lectularius) in human settlement area of Bahnamir, Iran. Asian Pac J Trop Dis. 2014;4:S786-S9. doi: 10.1016/s22221808(14)60727-1.

14) Giorda F, Guardone L, Mancini M, Accorsi A, Macchioni F, Mignone W. Cases of bedbug (Cimex lectularius) infestations in Northwest Italy. Vet Ital. 2013;49(4):335-40. doi: 10.12834/VetIt.1011.10. [PMID: 24362773].

15) How YF, Lee CY. Survey of bedbugs in infested premises in Malaysia and Singapore. J Vector Ecol. 2010;35(1):89-94. doi: 10.1111/j.1948-7134.2010.00033.x. [PMID: 20618653].

16) Omudu E, Kuse C. Bedbug infestation and its control practices in Gbajimba: a rural settlement in Benue state, Nigeria. J Vector Borne Dis. 2010;47(4):222. [PMID: 21178215].

17) Levy Bencheton A, Berenger J, Del Giudice P, Delaunay P, Pages F, Morand J, et al. Resurgence of bedbugs in southern France: a local problem or the tip of the iceberg? J Eur Acad Dermatol Venereol. 2011;25(5):599-602. doi: 10.1111/j.1468-3083.2010.03804.x.

18) El-Azazy O, Al-Behbehani B, Abdou N. Increasing bedbug, Cimex lectularius, infestations in Kuwait. J Egypt Soc Parasitol. 2013;43(2):415-18. doi: 10.12816/0006397.

19) Doggett SL, Russell RC. The resurgence of bedbugs, Cimex spp.(Hemiptera: Cimicidae) in Australia. InProceedings of the Sixth International Conference on Urban Pests 2008 Jul 13 (Vol. 6, pp. 407-425). Veszprem: OOK-Press Kft.

20) Kilpinen O, Jensen K-MV, Kristensen M, editors. Bedbug problems in Denmark, with a European perspective. Proceedings of the Sixth International Conference on Urban Pests; 2008: OOK-Press Veszprém.

21) Alizadeh I, Sharififard M, Jahanifard E. Cimex lectularius and prevent and control methods on human settlements. Tehran: Khosravi Publisher. 2016.

22) Alizadeh I, Sharififard M, Jahanifard E. Allergic reactions and dermatitis to common bedbug bites: Acase report from Ahvaz, southwest of Iran. Iran J Dermatol. 2017;20:65-7. 
23) Potter MF, Rosenberg B, Henriksen MJNPMA, Inc., Fairfax, VA, http://www. npmapestworld. org/documents/BBSurveyexecsummaryjuly26. pdf. Bugs without borders-executive summary. 2010.

24) Delaunay P, Blanc V, Del Giudice P, Levy-Bencheton A, Chosidow O, Marty P, et al. Bedbugs and infectious diseases. Clin. Infect. Dis. 2011;52(2):200-10. doi: 10.1093/cid/ciq102.

25) Shah SN, Fossa A, Steiner AS, Kane J, Levy JI, Adamkiewicz G, et al. Housing Quality and Mental Health: the Association between Pest Infestation and Depressive Symptoms among Public Housing Residents. J Urban Health. 2018;95(5):691-702. doi: 10.1007/s11524-018-0298-7. [PMID: 30141116]. [PMCID: PMC6181819].

26) Wang C, Eiden A, Singh N, Zha C, Wang D, Cooper R. Dynamics of bedbug infestations in three low income housing communities with various bedbug management programs. Pest Manag Sci. 2018;74(6):1302-10. doi: 10.1002/ps.4830. [PMID: 29243884].

27) Cooper RA, Wang C, Singh N. Evaluation of a model community - wide bedbug management program in affordable housing. Pest Manag Sci. 2016;72(1):45-56. doi: 10.1002/ps.3982. [PMID: 25644070].

28) Comack E, Lyons J. What happens when the bedbugs do bite? The social impacts of a bedbug infestation on winnipeg's inner-city residents: canadian centre for policy alternatives winnipeg; 2011.

29) Lyons J. The social impacts of bedbugs on inner-city residents. 2010. 